\title{
Indirect estimation of child mortality using 2011 census data in the Islamic Republic of Iran
}

Yaser Mokhayeri, ${ }^{1}$ Seyed Mohammad Riahi, ${ }^{2}$ Elahe Rafiei, ${ }^{2}$ Zahra Asadgol ${ }^{3}$ and Seyed Saeed Hashemi-Nazari ${ }^{4}$

${ }^{1}$ Department of Epidemiology and Biostatistics, School of Public Health and Nutrition, Lorestan University of Medical Sciences, Khorramabad, Islamic Republic of Iran. ${ }^{2}$ Department of Epidemiology, School of Pblic Health and Safety, Shahid Beheshti University of Medical Sciences, Tehran, Islamic Republic of Iran. ${ }^{3}$ Department of Environmental Health Engineering, School of Public Health, Iran University of Medical Sciences, Tehran, Islamic Republic of Iran. ${ }^{4}$ Prevention of Cardiovascular Disease Research Center, Department of Epidemiology, School of Public Health and Safety, Shahid Beheshti University of Medical Sciences, Tehran, Islamic Republic of Iran (Correspondence to: S. Hashemi-Nazari: saeedh_1999@yahoo.com).

\begin{abstract}
Background Child mortality rates are considered to be one of the key indicators of child health.

Aims The main objective of this research was to calculate child mortality rates (CMRs) indirectly, using census data, and to investigate using spatial pattern analysis the presence of any clustering patterns among provincial regions.

Methods The Trussell version of the Brass method and Coale-Demeny West model were used to estimate CMRs and life expectancy (LE) at birth. The analyses were performed using the QFive program of MORTPAK 4 software. For cluster analysis, local and global Moran's I indexes were measured.

Results Infant mortality rate, under-5 mortality rate, 1-4 mortality rate and LE at birth were estimated as 21.9, 26, 4.1 (deaths per 1000 live births) and 72.1 years, respectively. Global Moran's I index was calculated as 0.09, 0.09, 0.08 and 0.12, respectively.

Conclusion Special attention must be paid in provinces with high clusters regarding the evaluation of public health programmes, and the cause of failure of these programmes in reduction of childhood mortality indices.

Keywords: child mortality rate, infant mortality rate, spatial clustering, Islamic Republic of Iran, life expectancy.

Citation: Mokhayeri Y; Riahi SS; Rafiei E; Asadgol Z; Hashemi-Nazari SS. Indirect estimation of child mortality using 2011 census data in the Islamic Republic of Iran. East Mediterr Health J. 2020;26(2):161-169. https://doi.org/10.26719/2020.26.2.161

Received: 06/11/16; accepted: 23/04/18

Copyright (c) World Health Organization (WHO) 2020. Open Access. Some rights reserved. This work is available under the CC BY-NC-SA 3.0 IGO license (https://creativecommons.org/licenses/by-nc-sa/3.o/igo).
\end{abstract}

\section{Introduction}

For several decades, increasing attention has been paid to child mortality as a health indicator and as one of the Human Development Indices $(1,2)$. In 2000, the member countries of the United Nations agreed on the Millennium Development Goals (MDGs) for reducing the under-5 mortality rate (U5MR) by two thirds between 1990 and 2015 - known as the MDG 4 target (3). Globally, the number of under- 5 deaths has declined from 12.7 million in 1990 to 5.9 million in 2015. The U5MR has dramatically decreased from 91 per 1000 live births in 1990 to 43 in 2015.

The United Nations Inter-agency Group for Child Mortality Estimation (UN IGME) tries to update annual estimates (4); however, with the end of the MDG era, the international community has attempted to develop a new framework - Sustainable Development Goals (SDGs) $(5,6)$. SDGs propose a new commitment: by 2030, reducing neonatal mortality as low as 12 deaths per 1000 live births and $\mathrm{U}_{5} \mathrm{MR}$ as low as 25 deaths per 1000 live births (6).

Calculation of U5MR precisely is a key element in policy-making to develop different health strategies (7). In case of inaccessibility of incidence and prevalence data, mortality rates could be used to recognize vulnerable populations. Vital status registry systems and direct and indirect estimates based on sampling or census data are regarded as the main source of mortality rates
(8). Most developing countries have insufficient vital status registry systems to gather all deaths and births. In essence, most child mortality information is collected retrospectively from women of childbearing age (15-49 years) using census data and household surveys (1). In the Islamic Republic of Iran, like other developing countries, there is a lack of precise mortality data (9). These limitations necessitate using indirect methods such as the Brass method and its Trussell and Palloni-Heligman versions $(10,11)$.

The present study tried to detect clustering patterns of low or high incidence in any of these health indices among the geographic regions of the Islamic Republic of Iran, which is important from the viewpoint of public health (12). We aimed (1) to calculate child mortality rates (CMRs) indirectly using the Brass method (Trussell version) and census data, and (2) to recognize any clustering patterns among provincial regions by applying spatial pattern analysis. Hopefully, our results will pave the way for evidence-based decision-making.

\section{Methods}

\section{Data and Brass method}

We used a random sample of 2011 census data from the Statistical Center of Iran. The census data collection 
procedure is explained elsewhere (13). Stratified random sampling was adopted based on every urban-rural district and sampling fraction estimated as $2 \%$ for every district. The indices can be estimated directly or indirectly. The indirect method needs less information $(7,14)$, and we used that method for calculating the indices. Therefore, we needed information such as number of children ever born (CEB), number of children surviving (CS) and mother's age, which is available in the census data. In case $C E B$ and CS were missing, we replaced them with the mean CEB and mean CS for each maternal age group (15). The Trussell version of the Brass method was used for the Coale-Demeny West model to estimate CMRs and life expectancy (LE) at birth (Appendix 1) (10). This model is the most suitable for the Iranian population. The analyses were performed by QFive program of MORTPAK 4 software (UN software package for mortality measurements) (16).

The precise estimation of mortality depends on maternal age. In the indirect method, according to the estimated mortality rates for women in the different age groups from 15 to 45 years, CMRs are estimated (15). The estimates for women aged 20-24, 25-29 and 30-34 years are more accurate. Women aged 15-19 years usually underestimate reporting of children who are not born alive $(15,17)$. In recent years in the Islamic Republic of Iran, because of changes in the reproduction pattern of younger women, the estimated probabilities for the younger age groups that are closer to the census year are not accurate. Therefore, we set aside these estimates and used the estimated mortality rates for the age group of 30-34 years.

\section{Spatial clustering}

After calculating the childhood mortality indicators and LE for all 31 provinces, we plotted the results using a geographic information system to visualize the distribution of the above-mentioned indices across the country. We measured Global Moran's I and its local index Anselin local Moran's I to evaluate wethere there was any clustering or outliers among the provinces regarding the calculated indices (Appendix 2). Local Moran's I, is one of the Local Indicators of Spatial Association. This index shows the presence of clusters that are defined as accumulation of similar values - high or low. It is classified into 5 categories. The first category, Not Significant, denotes areas that are not significant at a default significance level of 0.05 and are not part of any clusters; High-High indicates clusters of high values surrounded by high values; Low-Low indicates clusters of low values surrounded by low values; Low-High denotes clusters of low values surrounded by high values; and High-Low denotes clusters of high values surrounded by low values. To measure Local Moran's I index, Inverse Distance as conceptualization of spatial relationships and Euclidean Distance as distance method were chosen.

Moreover, as a measure of spatial autocorrelation, we calculated Global Moran's I index. Generally, a positive Global Moran's I Index value indicates clustering, while a negative value indicates dispersion. It ranges from +1 to -1. Like the Local Moran's I index, Inverse Distance and Euclidean Distance were used as distance method and conceptualization of spatial relationships, respectively.

Finally, for hot spot analysis, Getis-Ord Gi index was measured. Fixed Distance Band as conceptualization of spatial relationships and Euclidean Distance as distance method were used. The Getis-Ord is an indicator of local clustering and assesses the presence of hot spots and cold spots.

\section{Results}

\section{Indirect estimation of IMR, U5MR, 1-4 mortality rate (1-4MR) and LE at birth}

Table 1 shows the population statistics by age groups. Using 2011 census data and estimation of women aged 30-34, IMR, U5MR, 1-4MR and LE (life expectancy) at birth $\left(e_{0}\right)$ were estimated as 21.9, 26, 4.1 deaths per 1000 live births and 72.1 years, respectively. IMR, U5MR, 1-4MR and LE at birth are shown in Table 2, which were calculated using the indirect method of QFive program of MORTPAK 4 software. The maximum childhood mortality - IMR, U5MR and 1-4MR -were calculated as 44.2, 57 and 12.8 per 1000 live births, respectively, in women aged 15-19 years. It should be noted that sex ratio of CEB (female to male) was 1.058. Child survival was estimated as $94.07 \%$. Female and male survival was calculated as $95.17 \%$ and $94.83 \%$, respectively.

Western and Southeastern Islamic Republic of Iran (including Sistan and Baloochestan, South Khorasan, Hamedan, West Azarbaijan, and Kordestan) had the maximum values for 1-4MR, IMR and U5MR, while the central and northern regions (including Tehran, Qom and Mazandaran) had the minimum values. Conversely, LE had minimum values in the west and southeast and maximum values in the centre and north (Figures 1A, 2A, 3A, 4A).

\section{Spatial clustering}

Table 3 presents Global Moran's I index value for childhood mortality indices and LE $\left(e_{0}\right)$. The highest clustering

\begin{tabular}{lccc}
\hline \multicolumn{2}{l}{$\begin{array}{l}\text { Table } 1 \text { Population statistics to calculate childhood mortality } \\
\text { in 2011 }\end{array}$} \\
$\begin{array}{lccc}\text { Maternal age } \\
\text { group (yr) }\end{array}$ & $\begin{array}{c}\text { Women of } \\
\text { childbearing } \\
\text { age }\end{array}$ & $\begin{array}{c}\text { Children } \\
\text { ever born }\end{array}$ & $\begin{array}{c}\text { Children } \\
\text { surviving }\end{array}$ \\
\hline $15-19$ & 3152384 & 196772 & 188445 \\
$20-24$ & 4086388 & 1579252 & 1522163 \\
$25-29$ & 432238 & 3751230 & 3647051 \\
$30-34$ & 3443474 & 5189562 & 5057633 \\
$35-39$ & 2723759 & 6079475 & 5883362 \\
$40-44$ & 2414373 & 7033094 & 6757567 \\
$45-49$ & 1995606 & 7320756 & 6961305 \\
\hline Total & $\mathbf{2 2 ~ 1 3 8 2 2 2}$ & $\mathbf{3 1} \mathbf{1 5 0 1 4 1}$ & $\mathbf{3 0} \mathbf{0 1 7 5 2 6}$ \\
\hline
\end{tabular}




\begin{tabular}{|c|c|c|c|c|c|}
\hline \multirow{2}{*}{$\begin{array}{l}\text { Maternal } \\
\text { age group } \\
\text { (yr) }\end{array}$} & \multirow[b]{2}{*}{$\begin{array}{l}\text { Reference } \\
\text { time) }\end{array}$} & \multicolumn{4}{|c|}{ Childhood mortality } \\
\hline & & IMR & $\mathbf{U}_{5} \mathrm{MR}$ & $1-4 M R$ & $\operatorname{LE}\left(e_{0}\right)$ \\
\hline $15-19$ & 2010.9 & 44.2 & 57 & 12.8 & 66.1 \\
\hline $20-24$ & 2009.6 & 34.6 & 43 & 8.4 & 68.4 \\
\hline $25-29$ & 2007.6 & 24.9 & 29.8 & 4.9 & 71.1 \\
\hline $30-34$ & 2005.2 & 21.9 & 26 & 4.1 & 72.1 \\
\hline $35-39$ & 2002.5 & 25.8 & 31 & 5.2 & 70.8 \\
\hline $40-44$ & 1999.7 & 28.7 & 34.9 & 6.2 & 69.9 \\
\hline $45-49$ & 1996.7 & 31.9 & 39.3 & 7.4 & 69.1 \\
\hline
\end{tabular}

${ }^{a}$ Trussell version of Brass method

$I M R=$ infant mortality rate; $\operatorname{LE}(e 0)=$ life expectancy at birth; $U_{5} M R=$ under-5 mortality rate.

(Global Moran's I index $=0.12$ ) was observed for LE $\left(e_{0}\right)$, while the lowest clustering - the highest dispersion - was estimated for $1-4 M R$ (Global Moran's I index $=0.08$ ). All Global Moran's I index values were statistically insignificant except for LE $\left(e_{0}\right)$.

Figures $1 \mathrm{~B}, 2 \mathrm{~B}, 3 \mathrm{~B}$ and $4 \mathrm{~B}$ show clustering analysis using the Anselin Local Moran's I method. Clustering for many provinces was not significant. The maps for both indices of $U_{5} M R$ and 1-4MR show the same pattern. High-High clustering was noted for Lorestan, Kermanshah, Kordestan and West Azarbaijan Provinces, and a High-Low outlier for Fras. Regarding IMR, Lorestan, Kordestan, Kermanshah, West Azarbaijan, East Azarbaijan, Hamedan and Markazi Provinces were High-High clusters, whereas Fras and Bushehr were High-Low outliers. For LE $\left(e_{0}\right)$, for provinces including Tehran, Qom, Qazvin, Gilan, Mazandaran, Markazi, Lorestan, Kermanshah, Zanjan, Alborz, Hemedan and Esfahan Provinces High-High clusters were estimated, and High-Low outliers for Fars and Bushehr.

Figures 5, 6, 7 and 8 show hot and cold spots for childhood mortality indices and LE at birth. Generally, IMR and U5MR showed the same pattern. Sistan and Baloochestan Province was observed as a hot spot, while Mazandaran and Qom Provinces were observed as cold spots. Regarding 1-4MR, Sistan and Baloochestan and South Khorasan Provinces were hot spots. Lastly,

Table 3 Global Moran's I index value for childhood mortality indices and life expectancy

\begin{tabular}{lccc} 
Index & Moran's I & SD & $\boldsymbol{P}^{*}$ \\
1-4 mortality rate & 0.08 & 0.07 & 0.11 \\
IMR & 0.09 & 0.07 & 0.08 \\
U5MR & 0.09 & 0.07 & 0.09 \\
LE (eo) & 0.12 & 0.07 & 0.03 \\
\hline
\end{tabular}

Data for 31 provinces

${ }^{*}$ significance level at $P<0.05$

$I M R=$ infant mortality rate; $L E(e o)=$ life expectancy at birth; $S D=$ standard deviation; $\mathrm{U}_{5} \mathrm{MR}=$ under-5 mortality rate.
Figure 1 Maps depicting 1-4 mortality rate across 31 provinces of Islamic Republic of Iran, 2011. A. Estimated distribution of 1-4 mortality rate. B. Cluster and outlier analysis (Anselin Local Moran's I).
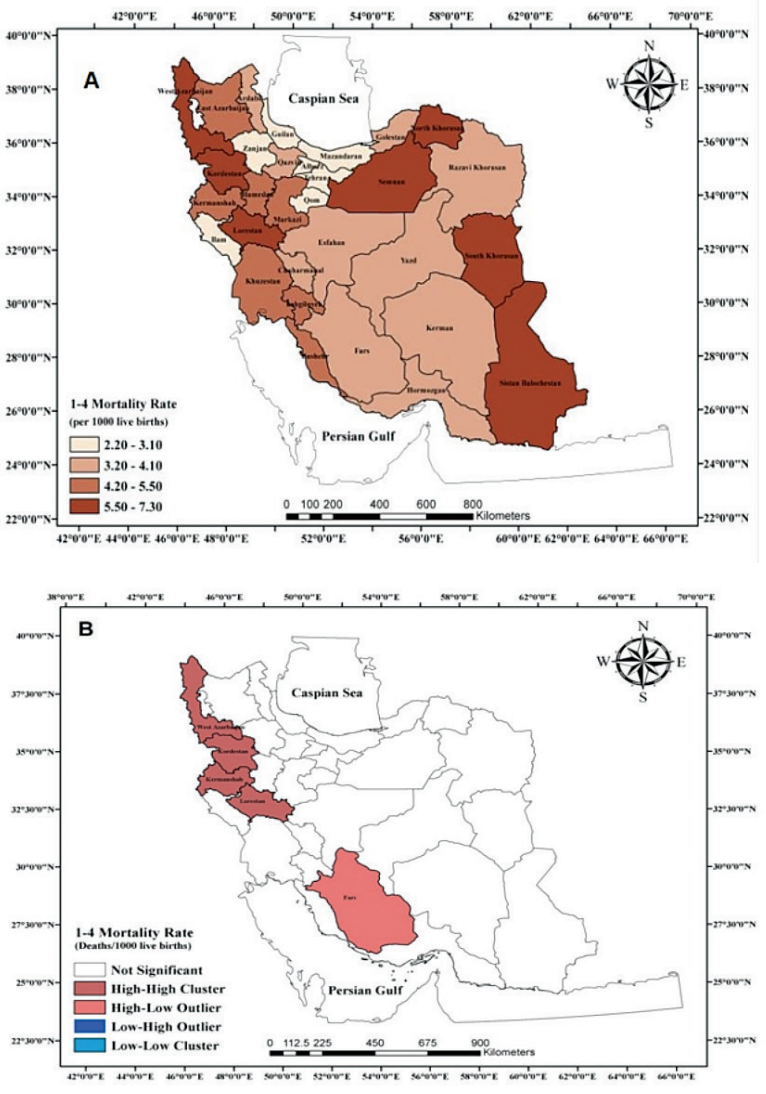

Figure 2 Maps depicting infant mortality rate across 31 provinces of Islamic Republic of Iran, 2011. A. Estimated distribution of infant mortality rate. B. Cluster and outlier analysis (Anselin Local Moran's I).
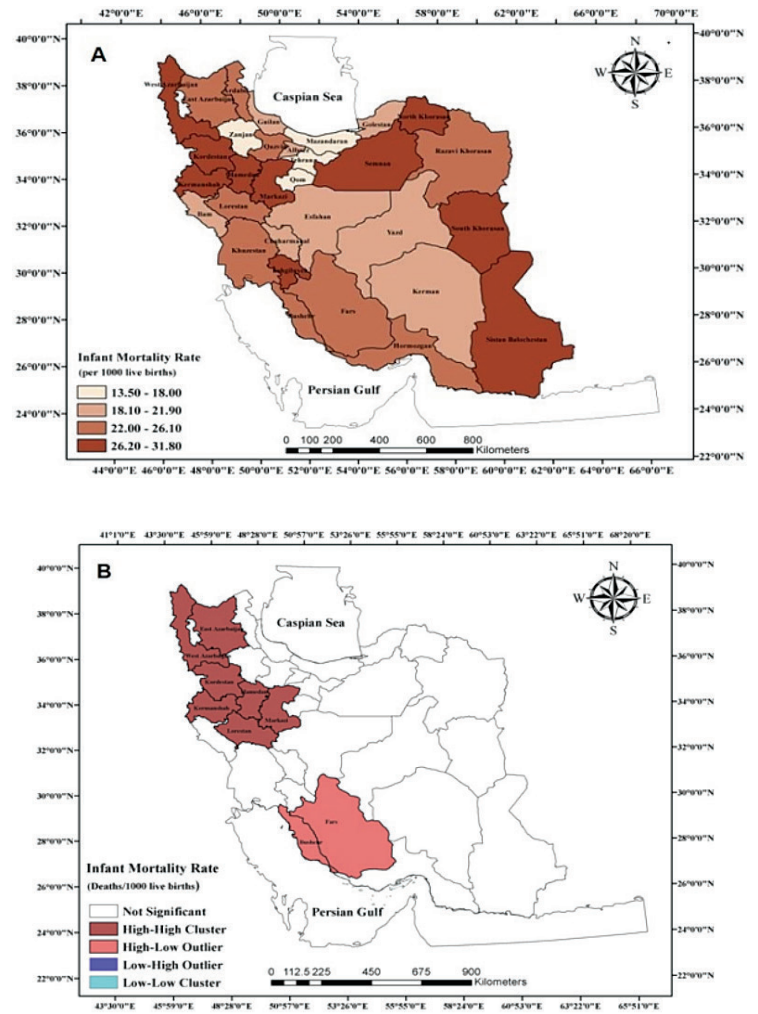
Figure 3 Maps depicting under-5 mortality rate across 31 provinces of Islamic Republic of Iran, 2011. A. Estimated distribution of under-5 mortality rate. B. Cluster and outlier analysis (Anselin Local Moran's I).
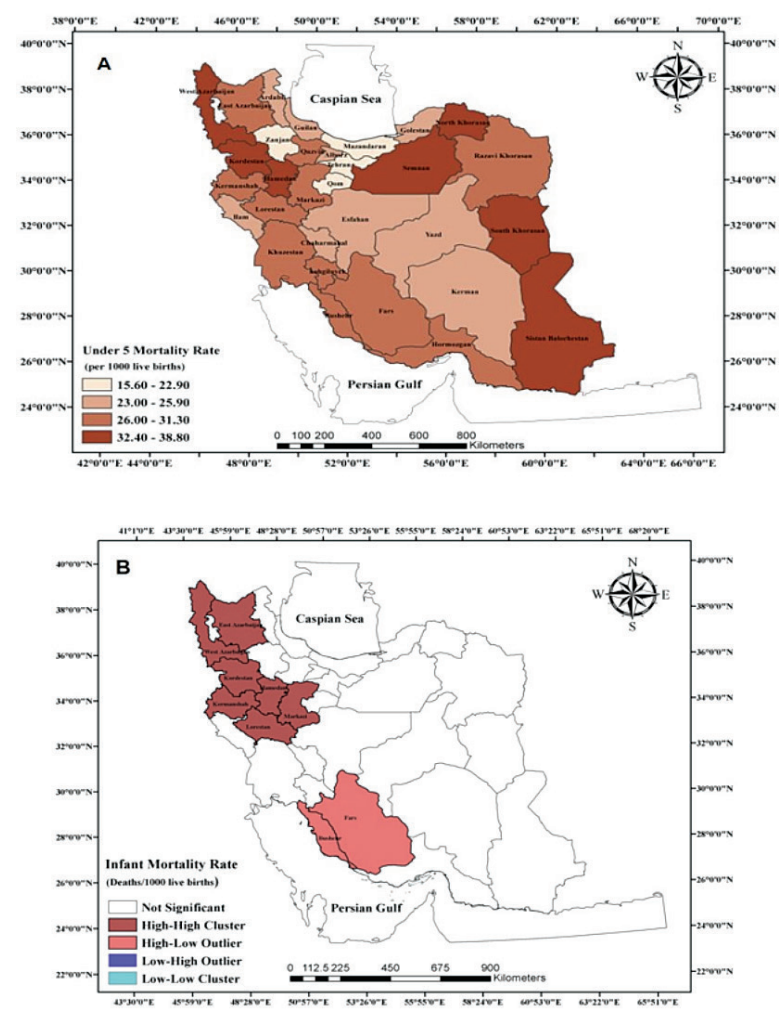

Figure 4 Maps depicting life expectancy across 31 provinces of Islamic Republic of Iran, 2011. A. Estimated distribution of life expectancy. B. Cluster and outlier analysis (Anselin Local Moran's I).
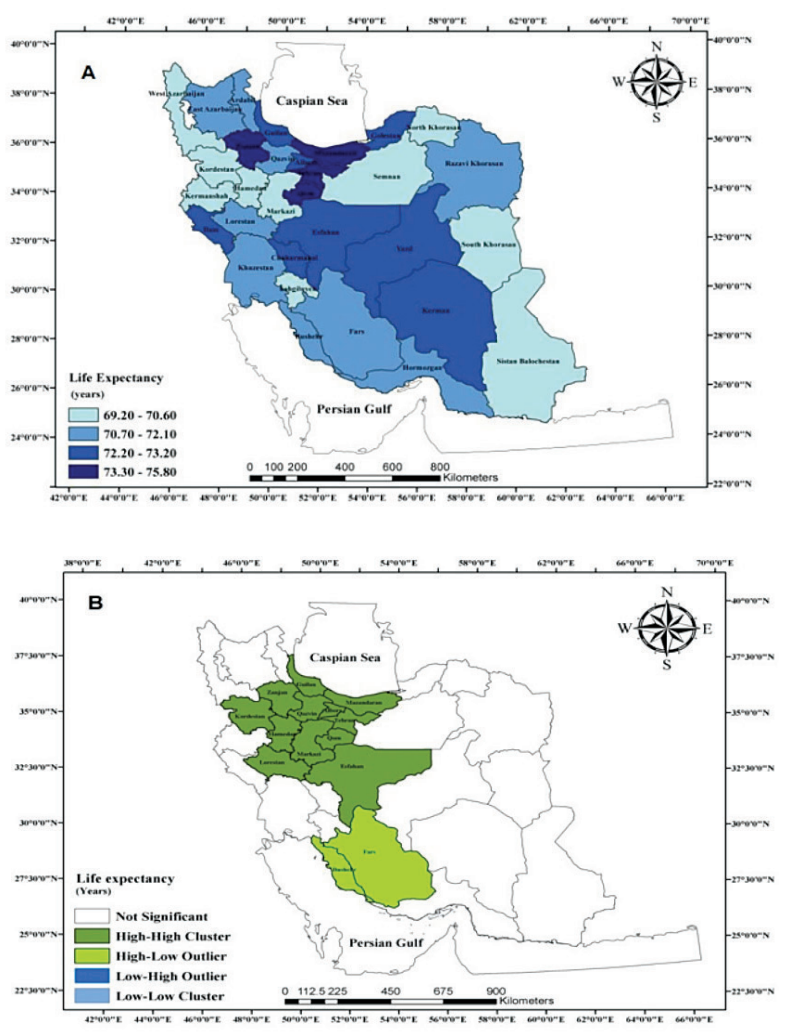

concerning LE (eo), Mazandaran and Qom Provinces were observed as hot spots; that is, provinces with the highest LE.

\section{Discussion}

In this study we tried to calculate CMRs indirectly using the Brass method (Trussell version) using census data, and to recognize any clustering regions using spatial pattern analysis. IMR, U5MR, 1-4MR and LE $\left(e_{0}\right)$ were estimated as 21.9, 26 and 4.1 deaths per 1000 live births and 72.1 years, respectively. Additionally, the western and northwestern regions showed High-High clusters for all indicators. Also, southeastern regions were observed as hot spots.

We used estimated values for women aged 30-34 years. Vapattanawong et al. also used this age group to estimate more precise CMRs (18). As mentioned before, reporting by women in older age groups suffers from low precision, and women in lower age groups usually underestimate death. However, in recent years in the Islamic Republic of Iran, because of changes in the reproductive pattern of younger women, the estimated probabilities for the younger age groups that are closer to the census year, are not accurate.

Across 31 provinces of the Islamic Republic of Iran, the gap between the maximum and minimum values shows a high variation in child mortality indicators and LE $\left(e_{0}\right)$ and was $18,23.5$ and 5.1 deaths per 1000 live births and 6.6 years for IMR, U5MR, 1-4MR and LE $\left(e_{0}\right)$, respectively.

Numerous studies have worked on spatial patterns of child mortality (19-23). However, we could not find any related studies in the Islamic Republic of Iran. In addition, little research has been conducted on child mortality using the Brass method in the Islamic Republic of $\operatorname{Iran}(9)$.

Mohammadi et al., using the summary birth history data from 4 data sources (3 censuses and Demographic and Health Survey), tried to estimate U5MR trends for all Iranian provinces during 1990-2015. Their estimations for 1990, 2000, 2010 and 2015 were 63.6, 38.8, 24.9 and 19.4 deaths per 1000 live births. Our estimate (in 2011) is similar to their result in 2010: 26 versus 24.9 deaths per 1000 live births. They calculated the highest and the lowest CMRs as 47 and 8.9 per 1000 live births for South Khorasan and Mazandaran Provinces. Similarly, we estimated U5MR for those provinces as the high and low mortality rates, respectively (24). Susuman used the Brass method (Trussell version) to calculate CMR in Ethiopia, which has gradually declined (17). Lee et al., used the indirect Brass method to calculate IMR and U5MR in Vietnam and showed that they have reduced significantly during 1986-2010 (25).

We suggest more studies to investigate the links between the aforementioned indicators and their probable causes. Social inequality might be a major cause of variation in infant mortality, which could be analysed appropriately using measures of segregation 
(26). Hashemi-Nazari et al. used a multilevel study on Iranian census data to estimate the effect of socioeconomic segregation on infant mortality and found controversial results. There was a negative association with education level, marital status and presence of a bathroom in the house, but a positive relation with age group, size of house, and ownership of a motorcycle (27). Kumar et al. studied geospatial analysis of $\mathrm{U}_{5} \mathrm{MR}$ in some states of India. They reported that health programme initiatives had a pivotal role in reducing $\mathrm{U}_{5} \mathrm{MR}$, even after adjusting for different variables such as population density, annual rainfall and average annual temperature (28). Singh et al. worked on geospatial analysis of IMR and U5MR in India. They believed that IMR and U5MR were higher in underprivileged regions in terms of child nutrition and female literacy. They also observed that, although, the effect of economic status on child malnutrition and child survival is weakening, the effect of maternal education is growing stronger (23). Gemperli et al. usedspatial analysis to identify the causes of geographic differences in IMR in Mali, using a Markov Chain Monte Carlo simulation. The results proved that maternal education, birth order and interval, infant sex, residence and mother's age had an important impact on IMR (19).

Vapattanawong et al. analysed 2 censuses using the Trussell version of the Brass indirect method by economic strata to measure changes in child mortality. The changes were not equal by different economic strata. In fact, the poorer parts of the population had a greater reduction in U5MR (18). El-khorazaty estimated child mortality for Bahrain, Egypt, Jordan, Kuwait, Syrian Arab Republic and United Arab Emirates using the Brass-Trussell methodology and Coale-Demeny West model life tables. These countries were not homogeneous in term of child mortality, reflecting disparities in health programmes, standards of living, and quality of life (29).

We concede a few limitations that were related to the assumptions of the indirect Brass method. This method can result in overestimation of child mortality. According to international estimation by the United Nations Children's Fund, child mortality in 2011 for the Islamic Republic of Iran was estimated as 18.4 (16.2-20.9) deaths per 1000 live births (30), while our estimate was 26 deaths per 1000 live births. In the Islamic Republic of Iran, U5MR has remarkably declined and was estimated as 58, 35 and 16 deaths per 1000 live births in 1990, 2000 and 2015, respectively. The annual rate of reduction was measured as $5.2 \%$ and considered sufficient to achieve MDG 4. In the Islamic Republic of Iran, MDG target for 2015 was defined as 19 deaths per 1000 live births (1). A further limitation was that the Brass method makes some demographic assumptions, such as stability of births and deaths, no relation between child death and mother's age, and accurate reporting of CEB and CS (31). Concerning the first assumption we used the estimated mortality rates for the maternal age group of 30-34 years, which has more stable production rates.
Figure 5 Hot spot analysis for 1-4 mortality rate across 31 provinces of Islamic Republic of Iran, 2011

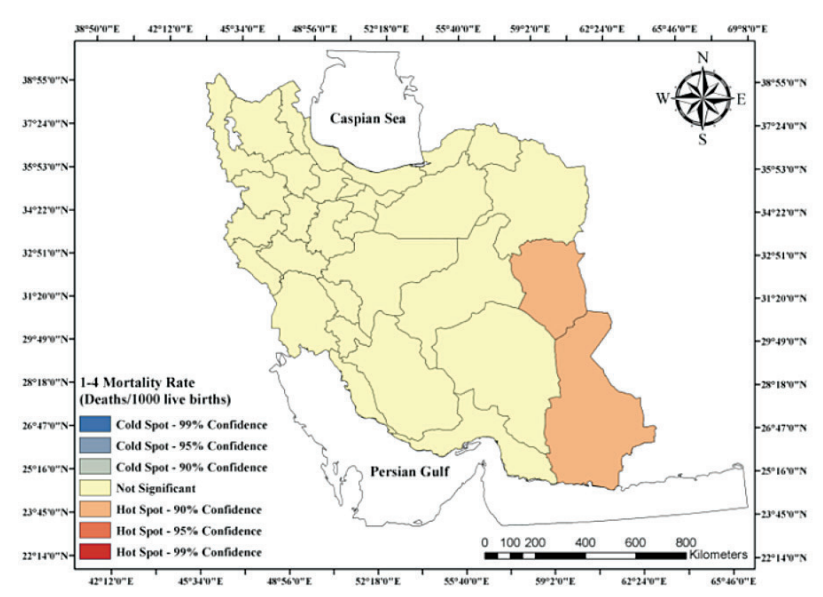

Figure 6 Hot spot analysis for infant mortality rate across 31 provinces of Islamic Republic of Iran, 2011

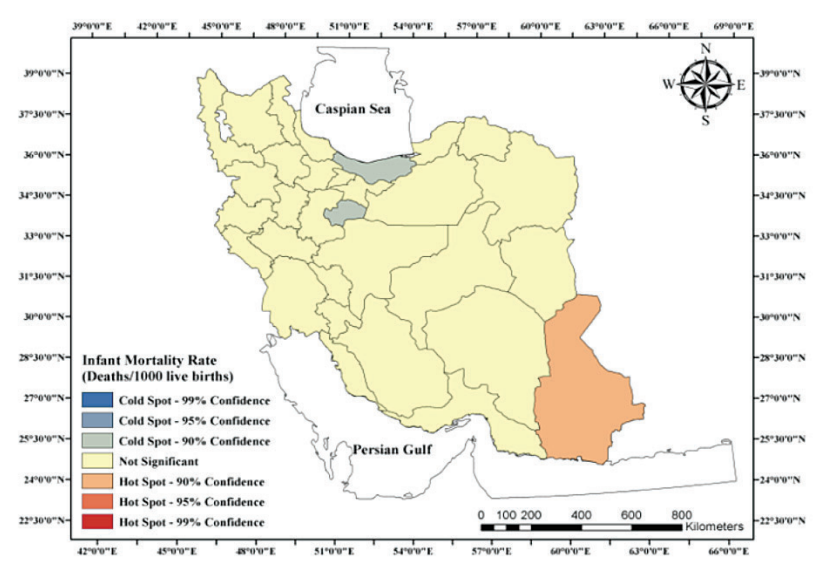

Figure 7 Hot spot analysis for under-5 mortality rate across 31 provinces of Islamic Republic of Iran, 2011

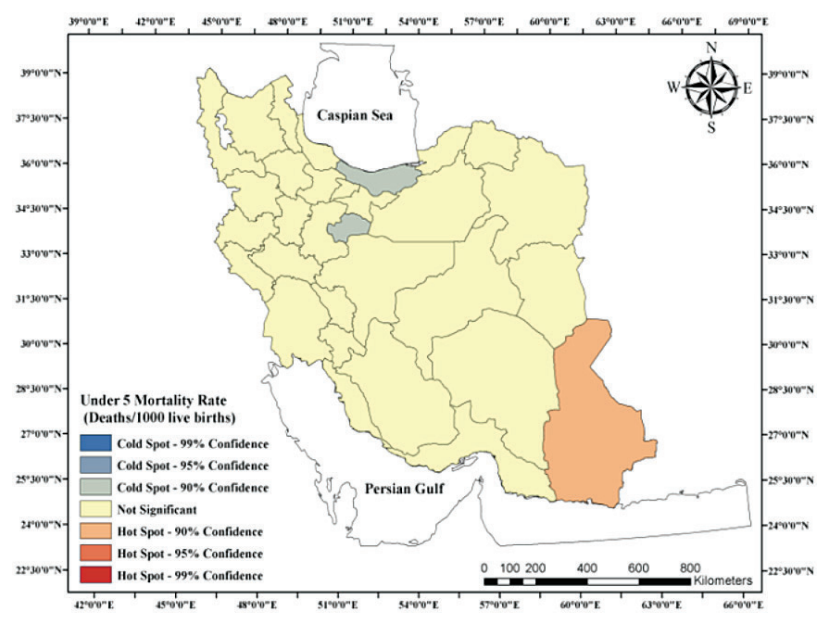


Figure 8 Hot spot analysis for life expectancy at birth across 31 provinces of Islamic Republic of Iran, 2011

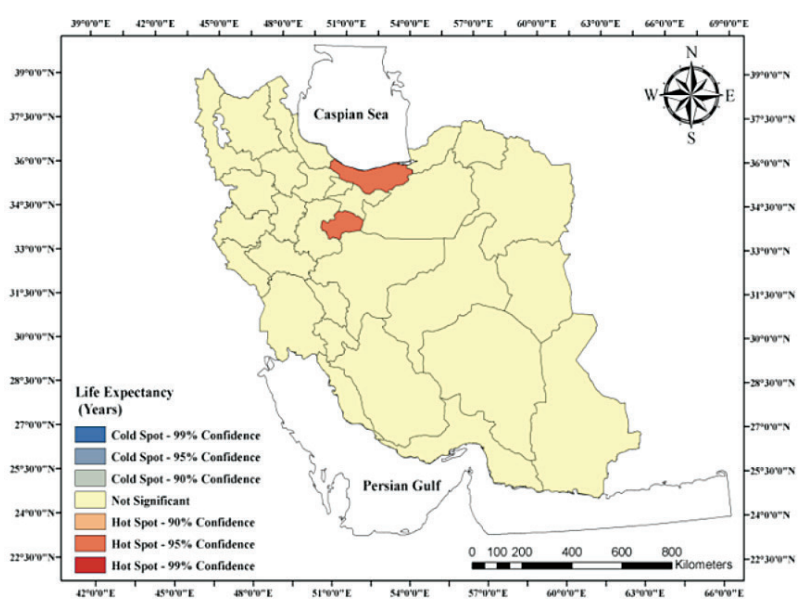

The main advantages of the study was using census data and spatial analysis tools for assessment of clustering patterns in CMRs and $\operatorname{LE}\left(e_{0}\right)$.

\section{Conclusion}

According to our finding, the western and northwestern regions of the Islamic Republic of Iran (including Lorestan, Kermanshah, Kordestan, and West Azarbaijan) were among the provinces with the highest CMRs, which formed a High-High cluster for IMR, U5MR, 1-4MR and LE. Special attention must be paid in these provinces regarding the evaluation of public health programmes, the cause of failure of these programmes in reducing childhood mortality indices, and the need for design and implementation of new public health programmes.

\section{Acknowledgements}

The authors would like to thank Mr. Alireza Badirzadeh (Shahid Beheshti University of Medical Sciences, Tehran, Islamic Republic of Iran) for his valuable input and advice in this paper. In addition, we are grateful to all staff at the Statistical Center of Iran for providing the population data.

\section{Funding: None.}

Competing interests: None declared.

\section{Appendix 1}

In this appendix, we describe the estimations process using the Trussell indirect method.

\section{Step 1: Calculating CEB for all age groups (i)}

This ratio could be calculated by division of CEB in each age group (i) by number of women in the same age group (i)

$$
\mathrm{P}_{\mathrm{i}}=\mathrm{CEB}_{\mathrm{i}} / \mathrm{FP}_{\mathrm{I}} \text {, where } \mathrm{FP}_{\mathrm{I}} \text { is fertility proportion }
$$

\section{Step 2: Calculating proportion of children deceased (CD) to CEB for each age group, $D_{i}$}

This ratio shows what proportion of CEB have died for each age group of women

$$
\mathrm{D}_{\mathrm{i}}=\mathrm{CD}_{\mathrm{i}} / \mathrm{CEB}_{\mathrm{i}}
$$

If during census CS have been questioned instead of $C D$, then the ratio is calculated as

$$
\mathrm{D}_{\mathrm{i}}=1-\mathrm{CS}_{\mathrm{i}} / \mathrm{CEB}_{\mathrm{i}}
$$

\section{Step 3: Estimation of $\mathrm{K}_{i}$ coefficients}

To estimating $q_{i}$ (death probability up to age $x$ ) it should be modified calculating of $\mathrm{D}_{\mathrm{i}}$. Therefore, we used a coefficient called $\mathrm{K}$

$$
K_{i}=a(i)+b(i)\left(\frac{P(19-15)}{P(20-24)}\right)+c(i)\left(\frac{P(20-24)}{P(25-29)}\right)
$$

The coefficients of $a(i), b(i)$ and $c(i)$ were estimated by a simulated regression analysis. These coefficients were estimated for all age groups and for 4 regions of Coale-Demeny life tables.

\section{Step 4: Estimation of death probability up to age $x$}

$q_{i}$ is estimated for each age group i using $D_{i}$ and $K_{i}$

$$
q_{i}=K_{i} D_{i}
$$

\section{Step 5: Defining reference time to death occurrence}

If death rate is changing at same rate, estimated $q$ based on census was linked to a definite time in the past. This reference time has a gap of few years from census year 


$$
t_{i}=e(i)+f(i)\left(\frac{P(19-15)}{P(20-24)}\right)+g(i)\left(\frac{P(20-24)}{P(25-29)}\right)
$$

The coefficients $e(i), f(i)$ and $g(i)$ were calculated using the Trussell method for each group of women and based on death pattern of Coale-Demeny.

\section{Appendix 2}

In this appendix, we describe 2 equations for calculating Moran's I index.

Moran's I define as:

(1) $\quad I_{i}=\frac{x_{i}-\bar{x}}{S_{i}^{2}} \sum_{j=1, j \neq i}^{n} w_{i, j}\left(x_{i}-\bar{x}\right)$

Where wi,j is the spatial weight between features $i$ and $j, n$ is equal to the total number of features, and $S_{0}$ is the aggregate of all the spatial weights:

(2) $\quad S_{0}=\sum_{i=1}^{n} \sum_{j=1}^{n} w_{i, j}$

\section{Estimation indirecte de la mortalité juvénile à l'aide des données du recensement de 2011 en République islamique d'Iran}

\section{Résumé}

Contexte : Les taux de mortalité juvénile sont considérés comme l'un des indicateurs clés de la santé de l'enfant.

Objectifs : La présente recherche visait principalement à calculer les taux de mortalité juvénile de façon indirecte, à partir des données du recensement. Elle avait aussi pour objectif de rechercher la présence de tendances de regroupement dans les régions provinciales au moyen d'une analyse de la structure spatiale.

Méthodes : La version de Trussell du modèle de Brass et le modèle Ouest des tables de Coale et Demeny ont été utilisés pour estimer les taux de mortalité juvénile et l'espérance de vie à la naissance. Les analyses ont été réalisées à l'aide du programme QFive du logiciel MORTPAK 4. Pour l'analyse en grappes, les indices de Moran local et global ont été mesurés.

Résultats : Le taux de mortalité infantile, le taux de mortalité des moins de 5 ans, le taux de mortalité des enfants de 1 à 4 ans et l'espérance de vie à la naissance ont été estimés à 21,9, 26, 4,1 (décès pour 1000 naissances vivantes) et 72,1 ans, respectivement. L'indice global de Moran I a été calculé à 0,09, 0,09, 0,08 et 0,12, respectivement.

Conclusions : Une attention particulière doit être portée aux provinces présentant des grappes importantes en ce qui concerne l'évaluation des programmes de santé publique et la cause de l'échec de ces derniers en termes de réduction des taux de mortalité juvénile.

$$
\begin{aligned}
& \text { التقدير غير المباشر لوفيات الأطفال باستخدام بيانات تعداد السكان لعام } 1 \text { ل ب ب في جمهورية إيران الإسلامية }
\end{aligned}
$$

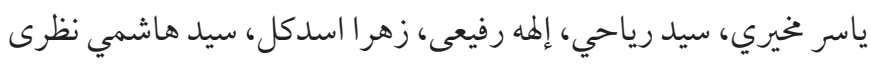

$$
\begin{aligned}
& \text { الخلفية: يُعتبر معدل وفيات الأطفال أحد المؤشرات الرئيسية لصحة الأطفال. }
\end{aligned}
$$

الأهداف: كان الهدف الأساسي من هذا البحث هو حساب معدلات وفيات الأطفال بطريقة غير مباشرة، باستخدام بيانات تعداد السكان،

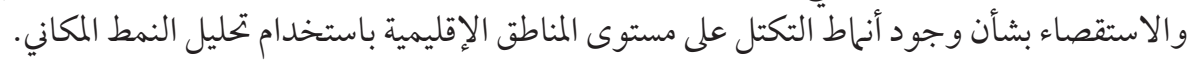

طرق البحث: استُخدمت نسخة تروسل الخاصة بطريقة براس ونموذج كول - ديمنى وست لتقدير معدلات وفيات الأطفال و مأمول العمر عند

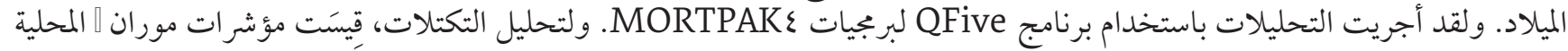
و العالمية.

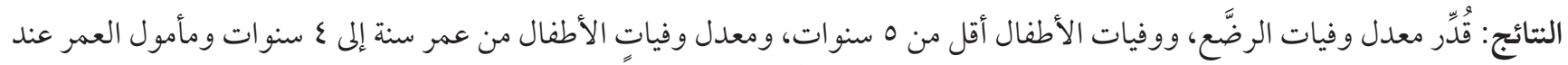

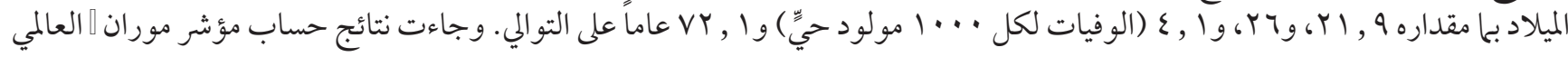
9

الاستنتاج: يجب إياء عناية خاصة في الأقاليم ذات التكتلات المرتفعة في ما يتعلق بتقييم برامج الصحة العامة، وسبب إخفاق هذه البرامج في خفض مؤشرات وفيات الأطفال. 


\section{References}

1. United Nations Department of Economic Affairs, Population Division. Level and trends in child mortality. Estimates developed by the UN Inter-agency Group for Child Mortality Estimation. New York: United Nations; 2015 (https://www.un.org/en/development/desa/population/publications/mortality/child-mortality-report-2015.asp, accessed 2 July 2019).

2. United Nations Development Programme (UNDP). Human Development Report 2010: The Real Wealth of Nations. New York: UNDP; 2010.

3. Garcia-Moreno C, Heise L, Jansen HA, Ellsberg M, Watts C. Violence against women. Science. 2005;310(5752):1282-3. http://dx. doi.org/10.1126/science.1121400 PMID:16311321

4. Oestergaard MZ, Inoue M, Yoshida S, Mahanani WR, Gore FM, Cousens S, et al. United Nations Inter-Agency Group for Child Mortality Estimation and the Child Health Epidemiology Reference Group. Neonatal mortality levels for 193 countries in 2009 with trends since 1990: a systematic analysis of progress, projections, and priorities. PLoS Med. 2011 Aug;8(8):e1001080. http:// dx.doi.org/10.1371/journal.pmed.1001080 PMID:21918640

5. Robert KW, Parris TM, Leiserowitz AA. What is sustainable development? Goals, indicators, values, and practice. Environment Sci Policy Sustain Dev. 2005;47(3):8-21. https://doi.org/10.1080/00139157.2005.10524444

6. Sachs JD. From millennium development goals to sustainable development goals. The Lancet. 2012 Jun 9;379(9832):2206-11. https://doi.org/10.1016/So140-6736(12)60685-0

7. Silva R. Child mortality estimation: consistency of under-five mortality rate estimates using full birth histories and summary birth histories. PLoS Med. 2012;9(8):e1001296. http://dx.doi.org/10.1371/journal.pmed.1001296 PMID:22952436

8. World development indicators 2013. Washington, DC: World Bank; 2013 (http://documents.worldbank.org/curated/ en/449421468331173478/pdf/768240PUBoEPIooICooPUBoDATE04012013.pdf, accessed 2 July 2019).

9. Khosravi A, Taylor R, Naghavi M, Lopez AD. Mortality in the Islamic Republic of Iran, 1964-2004. Bulletin of the World Health Organization. 2007 Aug;85(8):607-14. http://dx.doi.org/10.2471/blt.06.038802 PMID:17768519

10. United Nations Department of International Economic and Social Affairs. Population Studies No. 107. Step-by-step guide to the estimation of child mortality 1990. New York: UN; 1990 (https://www.un.org/en/development/desa/population/publications/pdf/ mortality/stepguide_childmort.pdf, accessed 2 July 2019).

11. Hill K, Trussell J. Further developments in indirect mortality estimation. Population Studies. 1977 Jul;31(2):313-34. http://dx.doi.or g/10.1080/00324728.1977.10410432 PMID:22077841

12. Robinson T. Spatial statistics and geographical information systems in epidemiology and public health. Adv Parasitol. 2000;47:81-128. PMID:10997205

13. Populations and housing censuses 2011. Tehran: Statistical Center of Iran (https://www.amar.org.ir/english/Population-and-Housing-Censuses, accessed 2 July 2019).

14. Rajaratnam JK, Tran LN, Lopez AD, Murray CJL. Measuring under-five mortality: validation of new low-cost methods. PLoS Med. 2010 Apr 13;7(4):e1000253. http://dx.doi.org/10.1371/journal.pmed.1000253 PMID:20405055

15. Mirzaei M. [A discourse on applied demography]. Tehran University; 2006 (in Persian).

16. Hinde A. Book Reviews: MORTPAK for Windows. Version 4.o. The United Nations software package for demographic measurement. Popul Stud. 2005;59(2):263-4. http://dx.doi.org/10.1080/00324720500099876

17. Susuman AS. Child Mortality Rate in Ethiopia. Iranian J Public Health. 2012;41(3):9-19. PMID:23113145

18. Vapattanawong P, Hogan MC, Hanvoravongchai P, Gakidou E, Vos T, Lopez AD, et al. Reductions in child mortality levels and inequalities in Thailand: analysis of two censuses. Lancet. 2007 Mar 10;369(9564):850-5. http://dx.doi.org/10.1016/So1406736(07)60413-9 PMID:17350454

19. Gemperli A, Vounatsou P, Kleinschmidt I, Bagayoko M, Lengeler C, Smith T. Spatial patterns of infant mortality in Mali: the effect of malaria endemicity. Am J Epidemiol. 2004 Jan 1;159(1):64-72. http://dx.doi.org/10.1093/aje/kwhoo1 PMID:14693661

20. Balk D, Pullum T, Storeygard A, Greenwell F, Neuman M. A spatial analysis of childhood mortality in West Africa. Population Space Place. 2004;10(3):175-216. http://dx.doi.org/10.1002/psp.328

21. Binka FN, Indome F, Smith T. Impact of spatial distribution of permethrin-impregnated bed nets on child mortality in rural northern Ghana. Am J Trop Med Hyg. 1998 Jul;59(1):80-5. http://dx.doi.org/10.4269/ajtmh.1998.59.80 PMID:9684633

22. Kandala N-B, Ghilagaber G. A geo-additive Bayesian discrete-time survival model and its application to spatial analysis of childhood mortality in Malawi. Quality Quantity. 2006 Dec;40(6):935-57. https://doi.org/10.1007/s11135-005-3268-6

23. Singh A, Pathak PK, Chauhan RK, Pan W. Infant and child mortality in India in the last two decades: a geospatial analysis. PLoS One. 2011;6(11):e26856. http://dx.doi.org/10.1371/journal.pone.0026856 PMID:22073208

24. Mohammadi Y, Parsaeian M, Mehdipour P, Khosravi A, Larijani B, Sheidaei A, et al. Measuring Iran's success in achieving Millennium Development Goal 4: a systematic analysis of under-5 mortality at national and subnational levels from 1990 to 2015. Lancet Global Health. 2017 May 1;5(5):e537-44. https://doi.org/10.1016/S2214-109X(17)30105-5

25. Lee H-Y, Do DV, Choi S, Trinh OTH, To KG. Trends and determinants of infant and under-five childhood mortality in Vietnam, 1986-2011. Global Health Action. 2016 Feb 29;9(1):29312. http://dx.doi.org/10.3402/gha.v9.29312 PMID:26950560 
26. Hashemi Nazari SS, Mahmoodi M, Holakouie Naieni K. Residential Segregation of Socioeconomic variables and health indices in Iran. Int J Prev Med. 2012 Jul;4(7):767-76. PMID:24049595

27. Nazari SH, Mahmoodi M, Mansournia M, Naieni KH. Residential segregation and infant mortality: a multilevel study using Iranian census data. Iranian J Public Health. 2012;41(4):69-79. PMID:23113167

28. Kumar C, Singh PK, Rai RK. Under-five mortality in high focus states in India: a district level geospatial analysis. PLoS One. 2012;7(5):e37515. http://dx.doi.org/10.1371/journal.pone.0037515 PMID:22629412

29. El-Khorazaty M. Indirect mortality estimates for children under five in six Arab countries. Popul Bull ESCWA. 1992(41-42):53105. PMID:12290057

30. Child mortality in Iran 2011. UN Inter-agency Group for Child Mortality Estimation (http://www.childmortality.org/index. php?r=site/graph\&ID=IRN_Iran, accessed 2 July 2019).

31. Nanda J, Adak DK, Bharati P. An assessment of infant and child mortality by social group and place of residence in districts of Orissa. Asian Pacific J Trop Dis. 2012 Dec;2:S242-53. 